\title{
Social networks on smoking, alcohol use and obesity among adolescents attending a school in the city of Lobos, Buenos Aires
}

\author{
Andrés H. Mulassi, $M D^{a}$, Raúl A. Borracci, $M D^{b}$, José G. E. Calderón, $M D^{a}$, \\ Patricio Vinay, $M D^{a}$ and Maximiliano Mulassi $M D^{a}$
}

\section{SUMMARY}

Introduction. The objective was to study different social networks of adolescents regarding the use of tobacco, alcohol use or obesity, in order to know to what extent friends and schoolmates influenced them in keeping or quitting these habits. Materials and Methods. Two hundred and ninety six adolescents aged 14-18 years attending an urban school in the province of Buenos Aires were surveyed and clinically studied. Information was obtained on anthropometric parameters, tobacco and alcohol use and friendship relations were assessed so as to construct different social networks.

Results: $18.8 \%$ of female adolescents and $16.5 \%$ of male adolescents were smokers; 23.3 and $39.4 \%$ drank alcohol and 15.3 and $19.0 \%$ were overweight. The networks showed that both smokers and alcohol users have close connections and a high level of centrality. The analysis showed that there is a strong affinity among people sharing the same habits.

Conclusions. The study of adolescent social networks allowed to show the relation of affinity among people having the habit of smoking, alcohol use or presenting obesity. Both smokers and alcohol users are closely connected in the network, while obese adolescents seem to stay marginal. Knowledge on social networks and the possibility of working on their members could be used to disseminate healthy behaviors among adolescents.

Key words: adolescence, smoking, alcohol, obesity, social network.

a. Council of

Cardiovascular

Epidemiology and

Prevention, Area

of Research of the

Argentine Society of

Cardiology.

Buenos Aires.

b. Bioestatistics,

School of

Biomedical Sciences, Universidad Austral, Argentina.

E-mail Address:

Raúl A. Borracci, MD:

raborracci@gmail.com

Conflict of Interest:

None.

Received: 02/28/2012

Accepted: 05/28/2012 aware of the risks related to smoking, alcohol consumption and overweight, their habits seem to contradict this awareness. ${ }^{3}$ The role of social networks in the maintenance and boosting of these habits has been recently studied in adults by Christakis and Fowler, ${ }^{4,5}$ who showed the impact of social bonds in the behavior when evaluating the spread of smoking and obesity in a large social network. Bonds developed in social networks seem to influence the behavior of individuals when they choose to smoke or watch their weight. ${ }^{6,7}$ The fact of having friends who smoke, use alcohol or are obese would increase the tolerance to these habits and the likelihood of adopting them.

Basically, a social network consists of a group of people who interact in a given setting. In a chart they are represented as a cluster of interconnected points and vectors. ${ }^{8-10}$

In a recent study on adolescents, it was found that the fact of having a friend, more than a relative, who smoked or used alcohol, increased by 4 to 10 times the likelihood of the adolescent being a smoker or alcohol user. ${ }^{11}$ This peer influence has been observed before, ${ }^{7}$ but there are no studies analyzing the topology of social networks of smokers, alcohol users or obese members among adolescents of Argentina. The study of these networks is warranted given the failure of other previously implemented prevention strategies. The objective was to study the structures of different social networks of adolescents regarding smoking, alcohol use and overweight or obesity so as to get information about the pathways of influence that friends might exert as far as keeping or quitting these habits. 


\section{MATERIAL AND METHODS}

In April 2010 an observational and cross sectional study was carried out on a group of adolescents from an urban public school in the city of Lobos, Buenos Aires, Argentina. The aim was to get information regarding their anthropometric and clinical parameters, food habits, smoking and alcohol use. Two hundred and ninety six students with ages ranging from 14 to 18 years old, attending the Basic General Education and polimodal school (from 2nd to 5th year) were studied by means of a self-administered survey and the direct measurement of some clinical parameters.

Demographic variables included were: age, sex, and year attending at school. Regarding food habits, a question about the steps taken to keep or put down weight was included. As far as smoking, questions were asked about having the habit or not; and, if the answer was positive, a question about frequency was asked. To estimate the different prevalence, smoking frequency was defined as follows: on one hand, conservatively, assuming the smoking of at least one cigarette in the last 6 months; on the other hand, daily smoking of at least one cigarette. To evaluate the behavior regarding alcohol use, a question was made regarding consumption and frequency. Alcohol use was defined as drinking alcohol at least 3 times a year. No data were collected about the social and economic profile. After providing some instructions on how to fill in the questionnaire, the students themselves completed it in front of investigators. The direct measurement of anthropometric and clinical parameters was made by the study investigators and it consisted of: weight, height, body mass index (BMI), waist circumference and blood pressure. To define overweight and obesity, the recommendations of the Consensus on risk factors of cardiovascular disease in pediatrics developed by the Argentine Association of Pediatrics, ${ }^{12}$ and a BMI between 25 and 30 for overweight and over 30 for obesity were used. The determination of the increase in waist circumference as body fat index was based on criteria from the same Consensus, assuming a cut-off point in the 90th percentile according to sex and age. ${ }^{12}$

\section{Building of friendship social networks}

In the same survey each student was asked to write down the first names and surnames of their best friends; they were allowed to write down from no names up to ten names. Students were only allowed to include friends who were their schoolmates so as to get to know the hab- its of those surveyed. This would not have been posible with the inclusion of friends out of their schoolmate circle. Each surveyed student was assigned a number to be able to identify him or her and each individual was considered as a node and each of their friends as a link to this new node. If the student was a smoker, alcohol user or overweight or obese, his or her name was highlighted in a different color so as to be able to identify him or her in the network. Based on these pieces of data, networks on smoking, alcohol use and obesity were developed and analyzed by means of the Kamada-Kawai algorithm ${ }^{13}$ in the Pajek software. ${ }^{14}$ Network development and analysis were defined as per the different parameters summarized in the Appendix (in the electronic version).

\section{Statistical Analysis}

Values were expressed as percentages or mean \pm standard deviation (SD). The odds ratio (OR) and the $95 \%$ confidence interval $(95 \% \mathrm{CI})$ and the corresponding $\chi^{2}$, Fisher or McNemar tests were estimated for statistical comparisons. Continuous variables were compared with the Student $t$ or Mann-Whitney tests, upon verification of distribution by means of the Kolmogorov-Smirnov test. All were two-tailed tests. Since this was a descriptive population sampling, the sample size was calculated with a $95 \%$ confidence, some estimated proportions of smoking, alcohol use and overweight of at least $15 \%$, and a maximum admissible error of $4 \%$. The estimated size was 306 subjects. The software packages used were Epi Info $2002^{\circledR}$ and SPSS $11.5^{\circledR}$.

Authorization was obtained from the local municipal authority and the General Inspection Board of Schools, in addition to the students' consent to participate or not. Parents were notified about the survey but no consent was requested from them.

\section{RESULTS}

Complete data were obtained from 285 (96.3\%) out of the 296 students surveyed. The (mean) age was $16.1 \pm 1.10$ years and $61.8 \%$ were girls. As far as smoking, $18.8 \%$ of girls and $16.5 \%$ of boys smoked at least a cigarette per day (OR: 0.86 ; $95 \%$ CI: $0.43-$ $1.68 ; \mathrm{p}=0.632$ ), while it increased to $30.7 \%$ and $27.5 \%$, respectively, when the question asked was if she or he had smoked at least one cigarette in the last 6 months (OR: 0.86; 95\% CI: 0.49-1.50; $\mathrm{p}=0.570$ ).

Alcohol consumption of 3 times or more a year was $39.4 \%$ among boys $23.3 \%$ among girls (OR: 2.15; 95\% CI: 1.24-3.73; $\mathrm{p}=0,004)$. 
When relating these two last variables without breaking them down by sex, $8.4 \%$ of adolescents smoked on a daily basis and used alcohol 3 or more times a year.
The percentage of female and male adolescents with overweight was $15.3 \%$ and $19.0 \%$, respectively (OR: 0.77; 95\% CI: 0.39-1.53; $\mathrm{p}=0.418$ ); while obesity was $3.5 \%$ and $1.9 \%$, respective-

FIGURE 1. Structure of the different social networks of adolescents according to their habits of smoking (a), alcohol use (b) and the presence of overweight or obesity (c). The darkest points in the networks indicate that the subject presents any of the conditions. Networks on the left correspond to the complete population of adolescents, while those on the right have been simplified to show only the relations of those who are smokers, alcohol users, or overweight or obese.

a. Complete and simplified social network of smokers. The smallest dark circles correspond to subjects who smoked in the last 6 months, while the larger ones correspond to those who smoke on a daily basis.
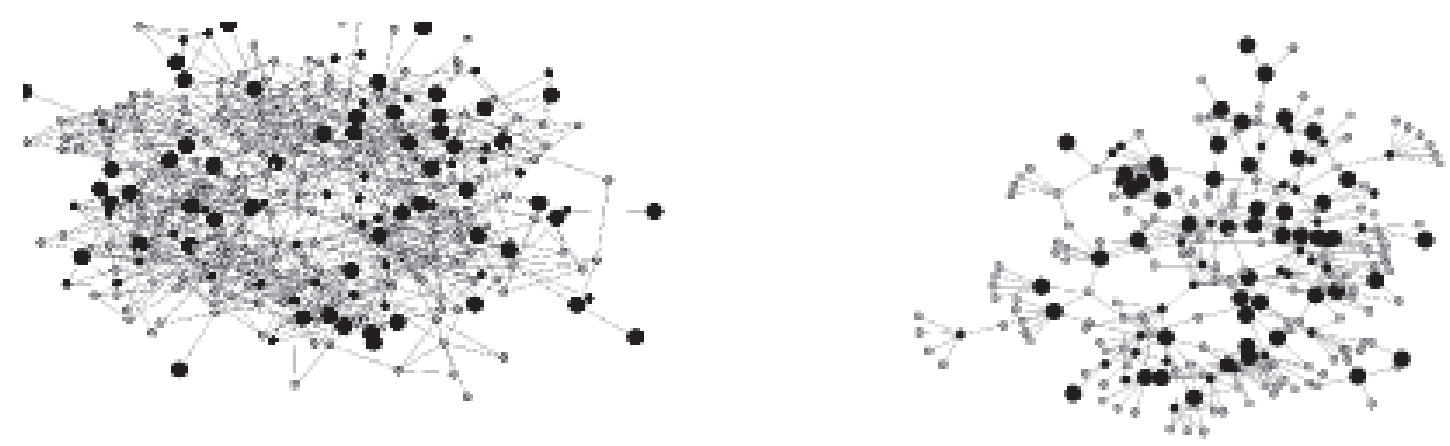

b. Complete and simplified social network of alcohol users (at least 3 times a year).
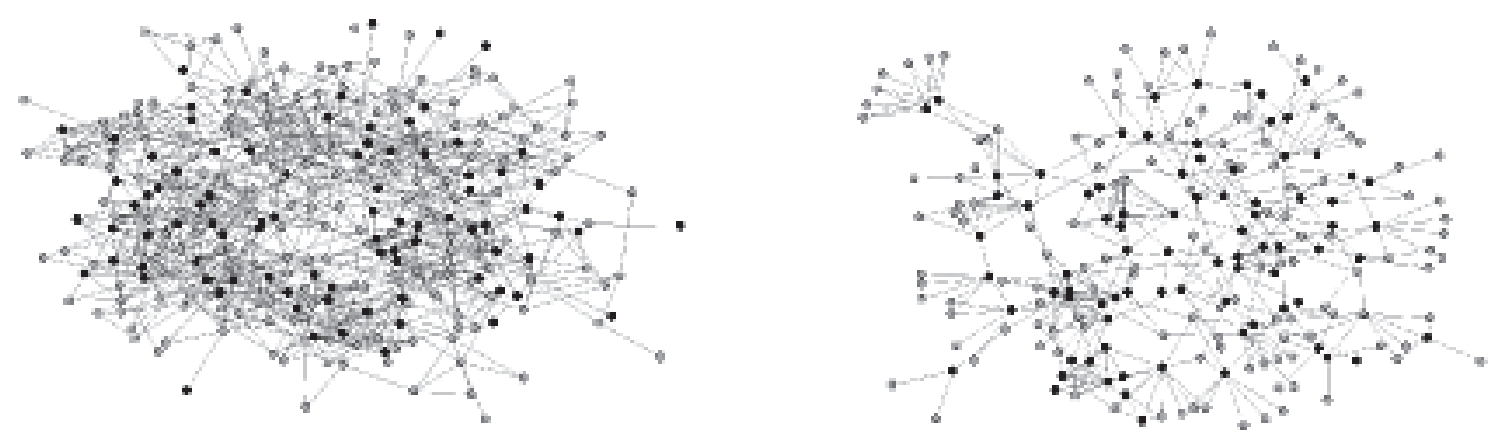

c. Complete and simplified social network of overweight and obese individuals. The smallest dark circles correspond to individuals with overweight while the larger ones correspond to obese students.
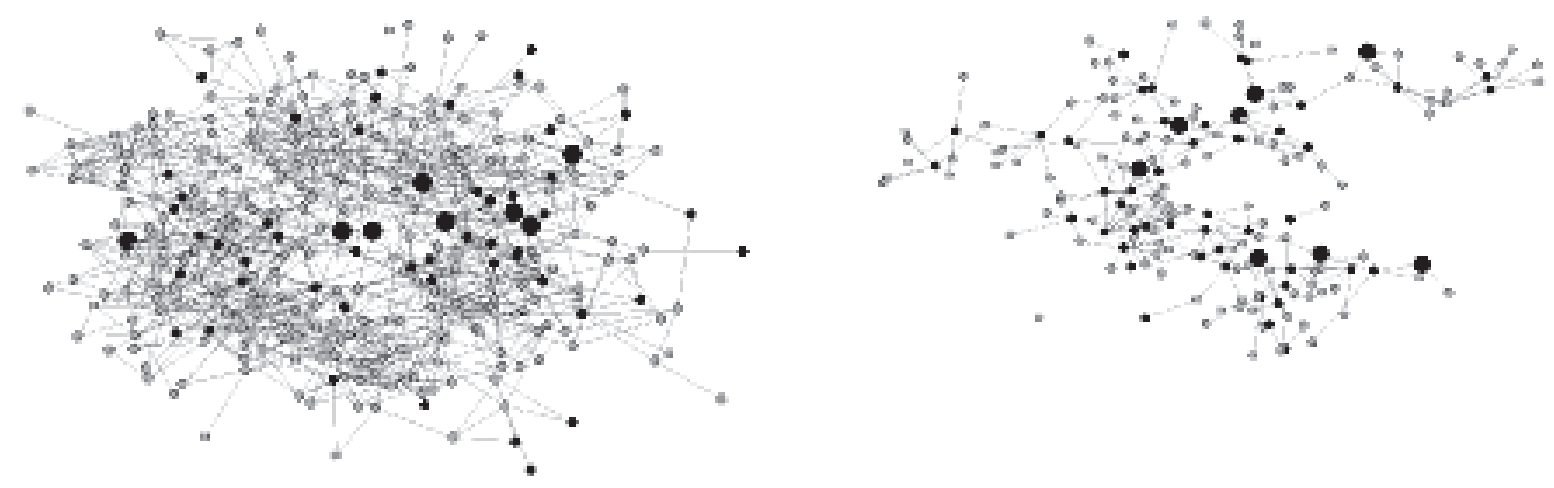
ly (OR: $1.88 ; 95 \%$ CI: 0.34-13.77; $\mathrm{p}=0.714)$. BMI was $22.1 \pm 3.57$ in girls and $21.9 \pm 3.33$ in boys $(\mathrm{p}=0.035)$; while waist circumference averaged $79.8 \pm 9.81 \mathrm{~cm}$ in girls and $81.6 \pm 9.43 \mathrm{~cm}$ in boys $(p=0.144)$. The percentage of female and male adolescents who said they watched their weight was $36.9 \%$ and $24.8 \%$, respectively (OR: $1.78 ; 95 \%$ CI: 1.01-3.14; $\mathrm{p}=0.033$ ). No relationship was found in female adolescents regarding smoking and weight control $(p=0.1525)$, taking into account that some girls smoke to control their weight (6.8\% watched their weight and smoked).

Systolic blood pressure readings for female and male adolescents were $109.1 \pm 14.95 \mathrm{mmHg}$ (minimum: 80, maximum: 160 ) and $115.9 \pm 14.27 \mathrm{mmHg}$ (minimum: 90, maximum: 170) $(\mathrm{p}=0,0002)$, respectively. Diastolic blood pressure readings for female and male adolescents were $62.5 \pm$ $11.74 \mathrm{mmHg}$ (minimum: 40, maximum: 100) and $66.1 \pm 10.39 \mathrm{mmHg}$ (minimum: 40, maximum: 90) $(\mathrm{p}=0,007)$, respectively.

\section{Social Networks}

Figure 1 shows networks built from data on smoking, alcohol use, and overweight and obesity. In the schematic representation on the left, the structure of networks with individuals who had the studied condition (dark nodes) and those who did not smoke, use alcohol nor were overweight or obese (light nodes) is shown. The lines represent friendship bonds. In the schematic representation on the right, individuals who are smokers, alcohol users or obese are plotted together with their friends while those adolescents who were

FIGURE 2. Charts in the box with centrality values of individuals in each network (centrality-closeness), according to the condition of smoking or not, drinking alcohol or not or being overweight or obese or not. The highest centrality values correspond to a higher degree of connectivity in the network and the lowest to a greater isolation in it. Data distribution is not Gaussian and the comparative Mann-Whitney $U$ test showed no difference among groups.

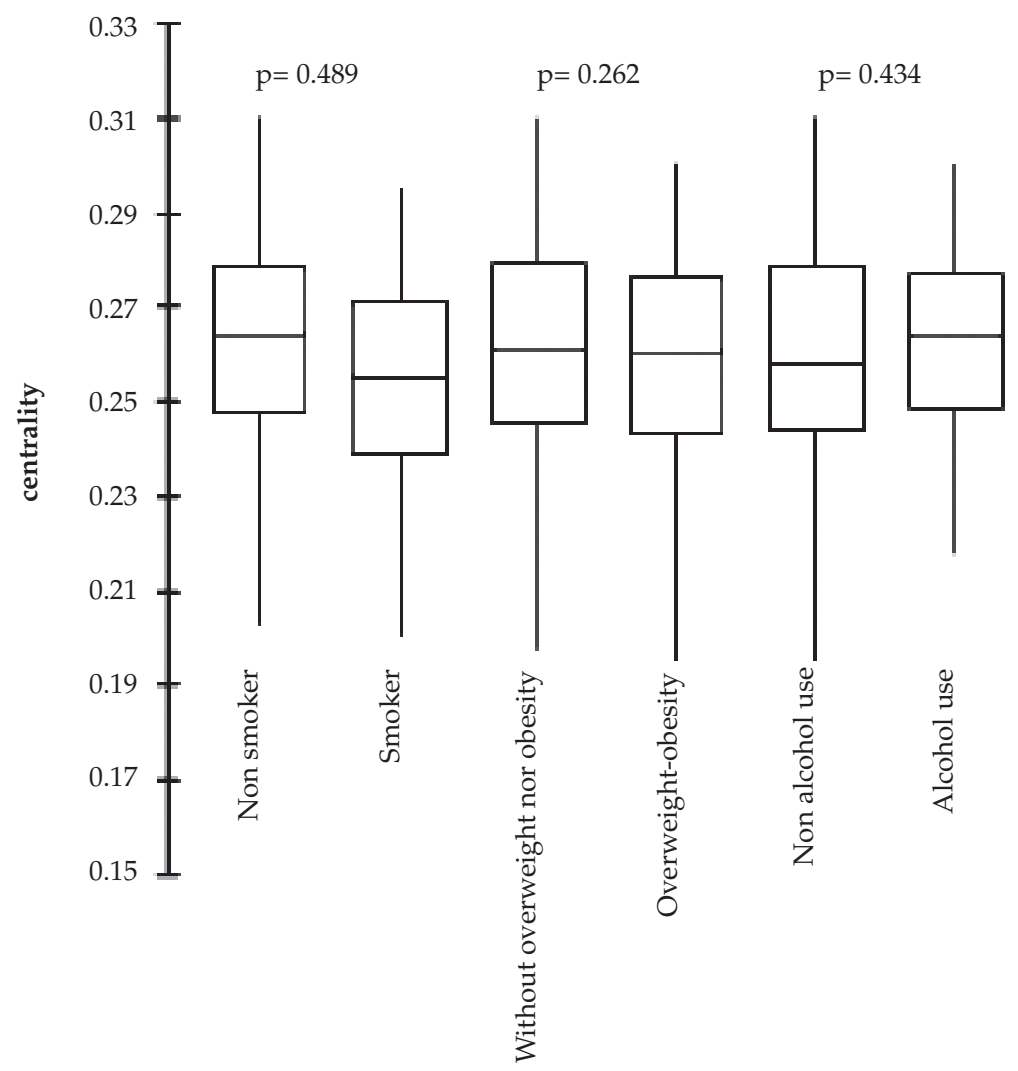


not part of the group of friends are excluded. The complete network had a diameter of 9 and an average distance separation of 3.90. Simplified networks of only smokers, alcohol users and obese adolescents with their friends had the following values: 15 and 6.16; 11 and 5.01; and 16 and 7.03, respectively.

Centrality values of individuals in each network according to the condition of smoking or non smoking, using or not using alcohol, having or not having overweight or obesity are stated in medians and quartiles in Figure 2. The highest centrality value was for smokers (mean: 0.261 , 95\% CI: 0.256-0.266) while the lowest value was for those who were overweight or obese (mean: 0.250; 95\% CI: 0.239-0.261). Additionally, the analysis of the average number of links (degree of connection) of adolescents in each group showed the following values: non smokers 11.1 \pm 5.46 versus smokers $10.2 \pm 4.64(p=0.139)$; non alcohol users $10.6 \pm 5.22$ versus alcohol users 11.5 $\pm 5.30(\mathrm{p}=0.176)$ and non obese $11.1 \pm 5.23$ versus obese $9.6 \pm 5.19(p=0.043)$, which shows a greater isolation of this group in the network.

The network of adolescents who smoke daily and their friends (simplified network) is shown on Figure 3. They are displayed on the chart ac- cording to their sex. Clusters of friends, with a predilection for the same sex, are observed. Small clusters from 2 to 5 individuals, unrelated to the giant component in the network, are apparent. The $C$ cluster coefficient of the complete network was $0.410 \pm 0.236$ and the estimated theoretical one for a random network would be 0.003 $(\mathrm{p}<0.001)$.

The degree of homophily or affinity for individuals with the same condition of smoker, alcohol user or obesity is represented in Figure 4 as the likelihood of having a friend who smokes, uses alcohol or is obese. In all the cases it can be seen that a smoker, alcohol user or obese adolescent has a higher likelihood of becoming related to an adolescent with the same condition than in the case of non smokers, no alcohol users or adolescents with a standard weight.

On Figure 5 the progress of a network is plotted according to the criterion used to define alcohol use. Given that sporadic alcohol use is very frequent, consecutive networks show how the density of alcohol users (dark nodes) grow as the definition of alcohol user is flexibilized; the sequence of graphs to the right underscores the rate of alcohol users according to the age in each network.

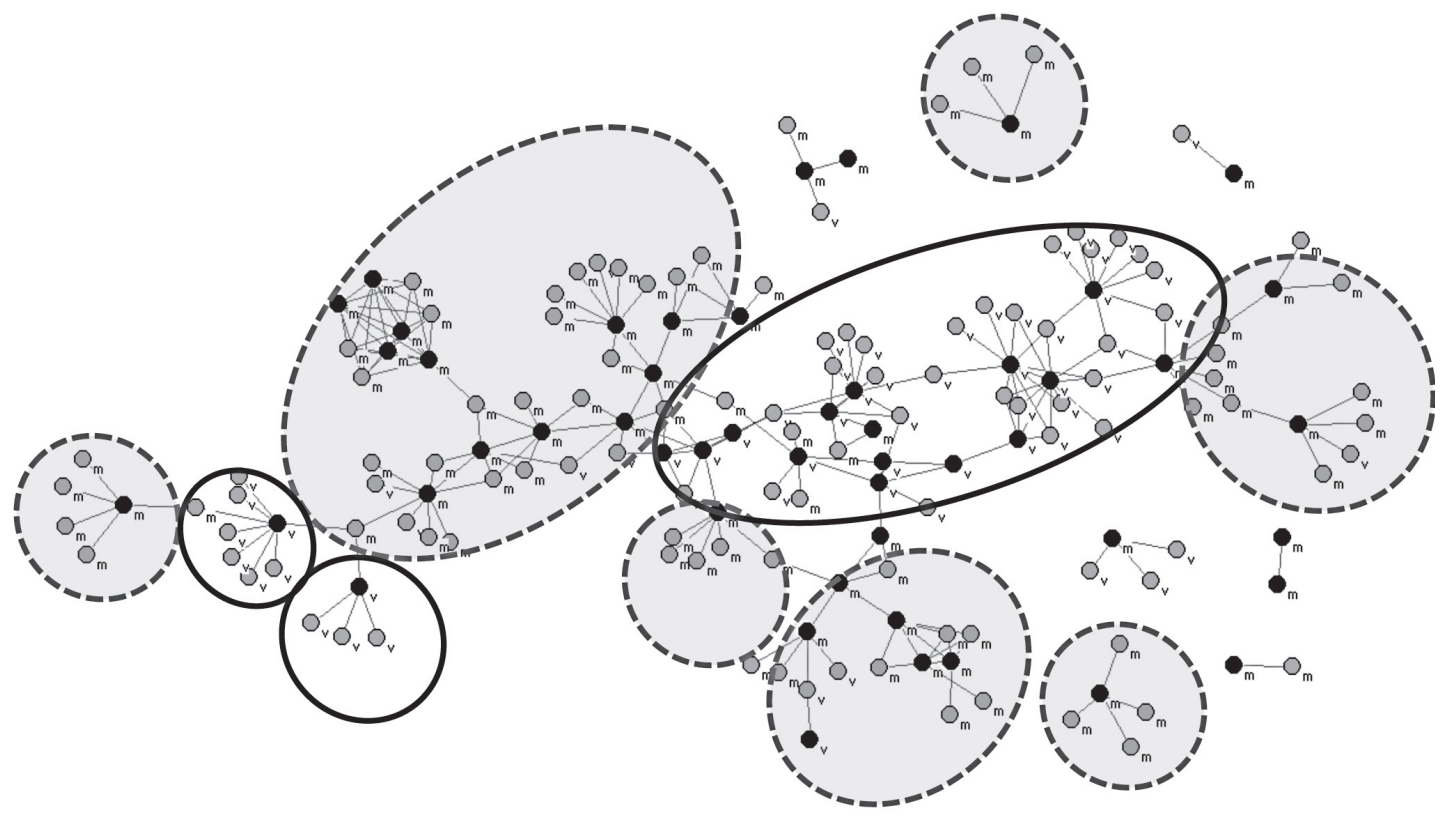




\section{DISCUSSION}

The interaction seen within a network favors the acquisition and development of habits that are repeated by imitation or affinity. ${ }^{4}$ In this study, the presence of adolescent smokers or alcohol users could modify the threshold of acceptance of these habits and the possible acquisition of them by accepting to share cigarettes or alcoholic beverages. In the case of obesity, there might be a similar mechanism, though the problem could have more genetic, cultural or fashion related components. When comparing the prevalence of smoking in this study to the one observed in a similar population, with a two years younger average age (16.1 versus 13.8 years), an increase from $6.8 \%$ to almost three more times was seen in boys $(18.8 \%) .{ }^{11}$ Compared to the same study, there were no differences in alcohol use preva- lence; this would point out that the habit of alcohol consumption could start early on. Regarding overweight and obesity, figures found are slightly lower than those reported by Kovalskys et al., ${ }^{15}$ in a national survey made ten years ago and for the same age group.

In contrast to what happens with adults, where smokers in their social networks occupy the periphery of the network, ${ }^{5}$ in adolescents, smokers location is as central as that of non smokers (centrality and degree of connection), showing youth's tolerance to the presence of smokers in their community. Alcohol users are also distributed within the network as if they were not, what points out that they are accepted right away. On the other hand, a lower degree of connection was observed in adolescents regarding overweight or obesity (9.6 versus 11.1, $\mathrm{p}=0.043)$, and this indi-

FIGURE 4. Box plots with values of homophily expressed as the likelihood of having a friend who smokes, drinks alcohol on a frequent basis, or is overweight or obese, according to the condition of smoking or not, using alcohol or not, or being overweight or obese or not. The highest values correspond to a higher likelihood of having a lead with the studied condition. Data distribution is not Gaussian and the comparative Mann-Whitney U test showed differences among groups; that is to say, smokers had a greater likelihood of having a friend who smokes than a non smoker, the same pattern was observed for alcohol users and obese adolescents.

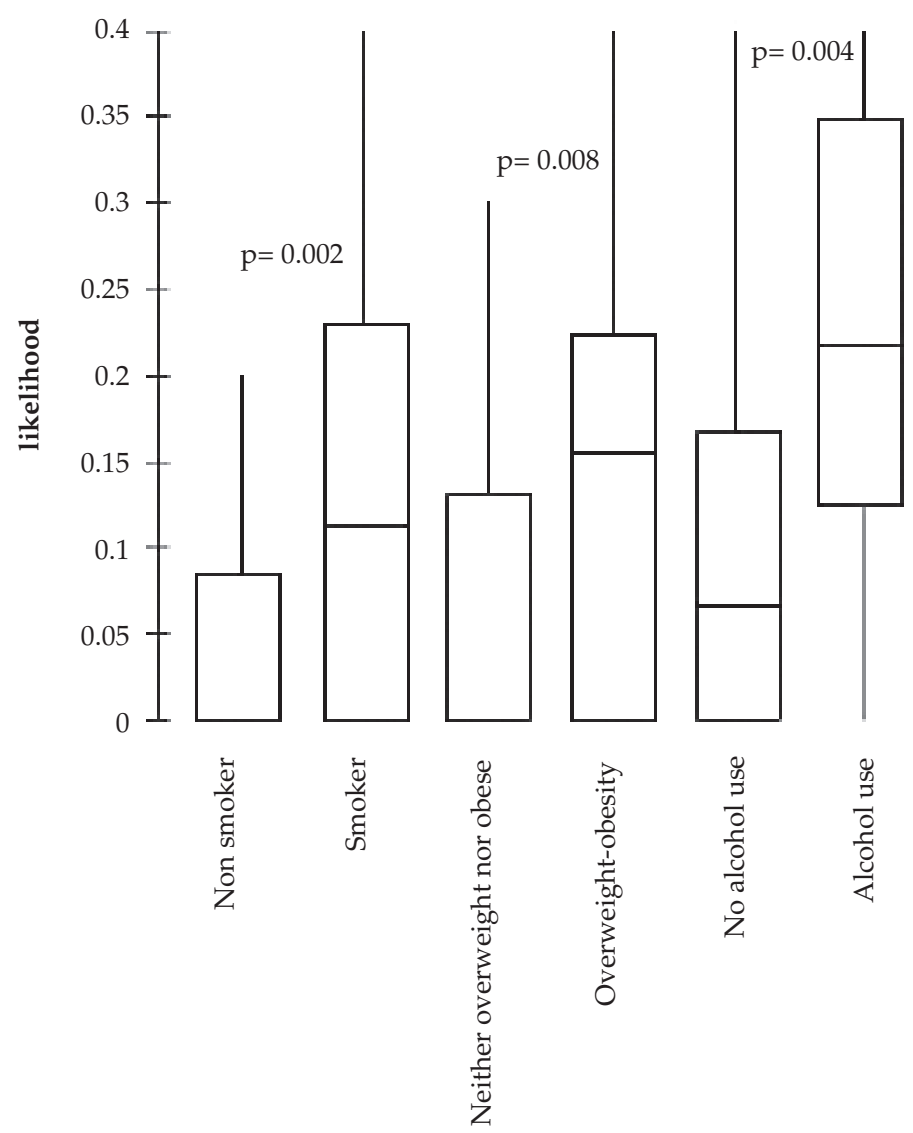


cates a greater isolation of this group in the network. This process of leaving aside adolescents with overweight has been corroborated by other authors. ${ }^{16}$

One characteristic observed is the trend to set up clusters of affinity based on sex, with the higher likelihood of female adolescents on one hand and male adolescents on the other one setting up friendship groups. For instance, even though it was not shown in this study, girls frequently say that they smoke to control their weight, while this is not the case with boys. ${ }^{17}$

The analysis of affinity among adolescents with the same habit (homophily) showed that a smoker is more likely to have a friend who smokes while a non smoker is less likely to become related to a smoker. The same likelihood relationship was found in alcohol users and obese adolescents. Likewise, it should be taken into account that adolescents with similar habits could be exposed to the same environment that makes them become obese or smokers or alcohol users, and that the alleged relationship of homophily could be the result of the covariation of this behavior. ${ }^{18}$

Christakis et $\mathrm{al}^{4}$ suggested that the social contact among adults is a spreading factor of obesity more than the exposure to other environmental factors. In adolescents, findings suggest that those

FIGURA 5. Development of adolescent network according to alcohol consumption: once a year (small dark circles), twice a year (mid-sized circles) and three or more times a year (large circles), together with percentages of alcohol users according to the age. The sequence of networks makes consumption definition broader and broader, from at least 3 times a year (a), at least twice a year $(b)$, and users regardless of annual frequency $(c)$.

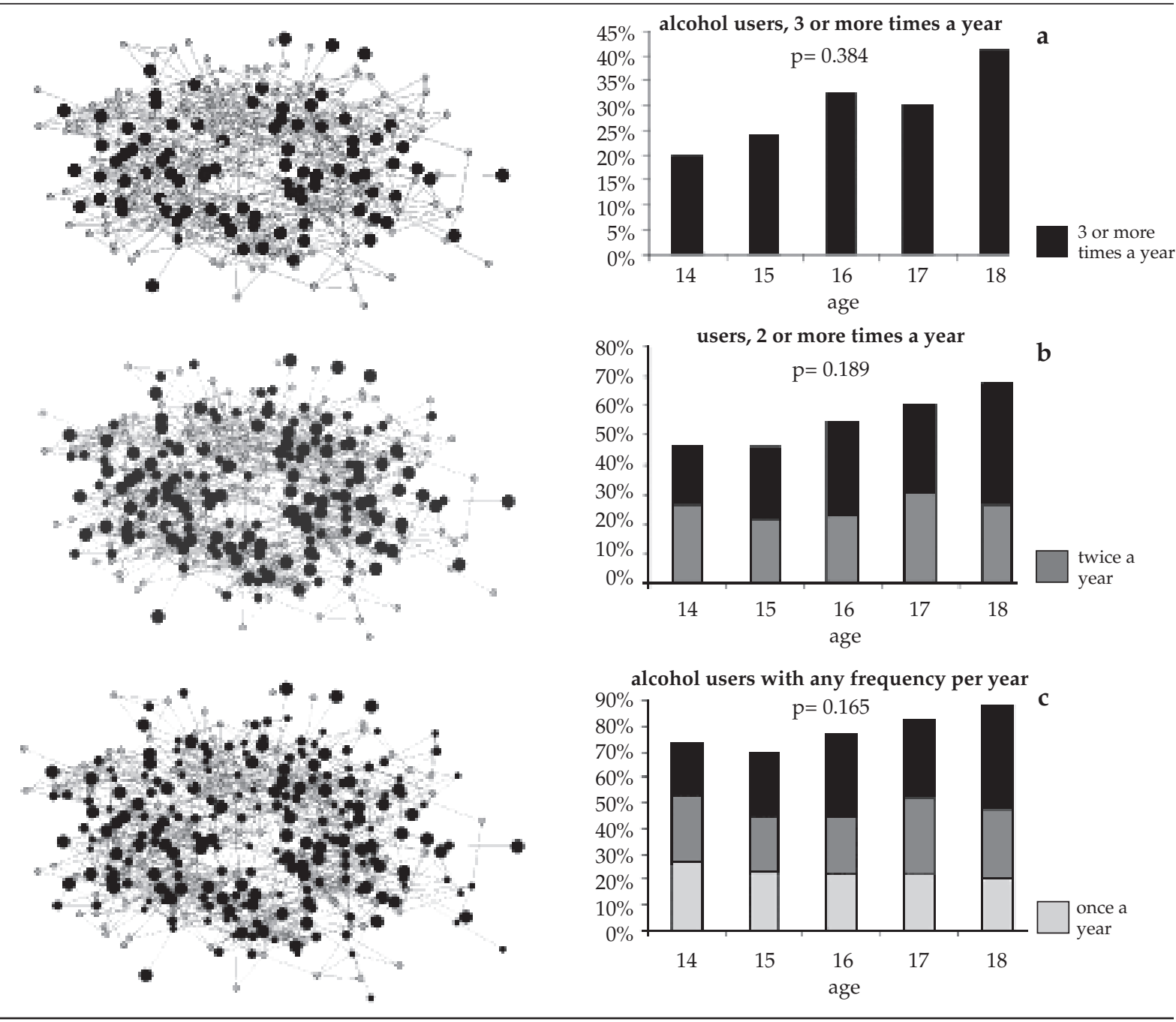


who are overweight or obese tend to occupy a less central place in networks and seem to have fewer friends, an isolation that would require a different epidemiological approach. Anyhow, homophily also showed that obese adolescents seem to have a stronger affinity with friends who have the same weight condition, that is to say, that the intervention on some of them could have an impact on the condition of the others.

As reported, if quitting smoking has a spreading effect from an individual to another one, health care intervention on a few of adolescent smokers with a high degree of connection in the network could multiply the wanted effect on their friends as a cascade..$^{19} \mathrm{~A}$ similar effect could be expected from interventions focused on reducing alcohol consumption. Thereby, network phenomena could be used to disseminate healthy behaviors among adolescents. ${ }^{20-22}$

Among the limitations of this study, it should be considered that the age range may be too wide to formulate friendships between groups, the same would happen to friendship between boys and girls. Social bonds among adolescents could be more unstable and changing, modifying the network architecture in a short time. Though friendship directionality (when one claims the friendship of someone else who perhaps does not consider her or him a friend) seems to have an influence on the acquisition of a habit like smoking or being overweight, ${ }^{4-5}$ it was not considered in our study because of the sample size. Another limitation is that obesity rates are not based on the BMI, age nor $\mathrm{Z}$ score, though we would like to clarify that this study was conducted in April 2010 and at that time we used the Consensus developed by the Argentine Association of Pediatrics in 2005. ${ }^{12}$ Later on, in 2011, the Argentine Association of Pediatrics developed the Guidelines on prevention, diagnosis and treatment of obesity, ${ }^{23}$ in which WHO Z score was recommended. Anyhow, the differences between our methodology and the $\mathrm{Z}$ score were evaluated. Since the present sample consisted of adolescents between 14 and 18 years old, the comparison of 25-30 age range and $>30$ for overweight and obesity were compared with the Z scores Z 1-2 and Z $\geq 2$ showing that, at most, the true prevalence of obesity has been underassessed.

Finally, the size of the sample used was somewhat smaller than that proposed in the design; however, the difference was small and it also depended on the size of the adolescent schoolmate group with potential bonds of friendship.

\section{CONCLUSION}

The study of social networks of adolescents enabled to know the affinity relations among those youngsters who have the habit of smoking, using alcohol or who are overweight or obese. Both smokers and alcohol users seem to be closely related in the network while those with overweight would occupy a more marginal place. Cluster formation favors contact among those who share the same habits, which reinforces the behavior but, in turn, would make healthcare intervention easier. The fact of knowing how social networks are developed and the intervention on only some of their members could be used to disseminate healthy behaviors among adolescents.

\section{BIBLIOGRAPHY}

1. Van Jaarsveld CH, Fidler JA, Simon AE, Wardle J. Persisten impact of pubertal timing on trends in smoking, food choice, activity, and stress in adolescence. Psychosom Med 2007;69(8):798-806.

2. Melchior M, Chastang JM, Goldberg P, Fombonne E. High prevalence rate of tobacco, alcohol and drug use in adolescents and young adults in France: results from the GAZEL youth study. Addict Behav 2008;33:122-33.

3. Smalley SE, Wittler RR, Oliverson RH. Adolescent assessment of cardiovascular heart disease risk factor attitudes and habits. J Adolesc Health 2004;35:374-9.

4. Christakis NA, Fowler JH. The spread of obesity in a large social network over 32 years. N Engl J Med 2007;357:370-9.

5. Christakis NA, Fowler JH. The collective dynamics of smoking in a large social network. N Engl J Med 2008;358:2249-58.

6. Chen PH, White HR, Pandina RJ. Predictors of smoking cessation from adolescence into adulthood. Addict Behav 2001;26:517-29.

7. Powell LM, Tauras JA, Ross H. The importance of peer effects, cigarette prices and tobacco control policies for youth smoking behavior. J Health Econ 2005;24:950-68.

8. Girvan M, Newman MEJ. Community structure in social and biological networks. Proc Natl Acad Sci USA 2002; 99:8271-6.

9. Newman MEJ. The structure and function of complex networks. SIAM Review 2003;45:167-256.

10. Bearman PS, Moody J, Stovel K. Chains of affection: the structure of adolescent romantic and sexual networks. Am J Sociol 2004;110:44-91.

11. Mulassi AH, Hadid C, Borracci RA, Labruna MC, et al. Hábitos de alimentación, actividad física, tabaquismo y consumo de alcohol en adolescentes escolarizados de la provincia y el conurbano bonaerense. Arch Argent Pediatr 2010;108(1):45-54.

12. Subcomisón de Epidemiología y Comité de Nutrición. Consenso sobre factores de riesgo de enfermedad cardiovascular en pediatría. Obesidad. Arch Argent Pediatr 2005;103(3):262-81.

13. Kamada T, Kawai S. An algorithm for drawing general undirected graphs. Information Processing Letters 1989;31:7-15.

14. Batagelj V, Mrvar A. Pajek - analysis and visualization of large networks. In: Junger M, Mutzel P, eds. Graph drawing software. Berlin: Springer; 2003. Pages. 77-103.

15. Kovalsky I, Bay L, Rausch Herscovici C, Berner E. Prevalencia de obesidad en una población de 10 a 19 años en la consulta pediátrica. Arch Argent Pediatr 2003;101(6):441-7. 
16. Strauss RS, Pollack HA. Social marginalization of overweight children. Arch Pediatr Adolesc Med 2003;157:746-52.

17. Eisenberg D, Quinn BC. Estimating the effect of smoking cessation on weight gain: an instrumental variable approach. Health Serv Res 2006;41:2255-66.

18. McPherson M, Smith-Lovin L, Cook JM. Birds of a feather: homophily in social networks. Anпu Rev Sociol 2001;27: 415-44.

19. Centola D, Eguiluz V, Macy M. Cascade dynamics of complex propagation. Physica A 2007;374:449-56.
20. Christakis NA. Social networks and collateral health effects. BMJ 2004;329:184-5.

21. Wing RR, Jeffery RW. Benefits of recruiting participants with friends and increasing social support for weight loss and maintenance. J Consult Clin Psychol 1999;97:132-8.

22. Pampel FC. Diffusion, cohort change, and social patterns of smoking. Soc Sci Res 2005;34:117-39.

23. Comité Nacional de Nutrición, Sociedad Argentina de Pediatría. Guías de práctica clínica para la prevención, el diagnóstico y el tratamiento de la obesidad. Arch Argent Pediatr 2011; 109(3):256-266. 
Appendix

\section{DEFINITIONS OF THE DIFFERENT PARAMETERS TO BUILD NETWORKS}

- Individual or ego: person whose condition and behavior is to be studied; in this case, each adolescent in his or her condition of smoker, alcohol user or obese.

- Friend or alter ego: represents each subject connected to the individual being studied, who could influence his or her behavior through a social network.

- Node: represents objects that are connected or not to a network; in this case, each node corresponds to an individual or friend.

- Bond or connection: graphic representation of a relationship between two nodes; in this case of friendship between two adolescents.

- Degree of connection: represents the number of connections of each individual in the network; in this case, the number of friends reported by each surveyed adolescent.

- Cluster: corresponds to a set of nodes, each of them connected to at least another node within the same group.

- Homophily: represents individuals' trend to relate to others with similar affinities or attributes. A way to state it is through the likelihood of an individual with a given attribute to relate to others with the same attributes.

- Centrality: once the network is built, centrality measures how close individuals are from their center. Those with the greatest number of connections occupy the most central place in the network and vice versa. On one hand, the degree of connection of each individual is a good measure of centrality; on the other hand, the coefficient of centrality (centrality-closeness) of each individual of the network can be calculated; the highest values would indicate a greater degree of connectivity in the network and the lowest the greater isolation in it.

- Giant or connected component of the network: in those networks with a small number of connections, individuals frequently belong to small islands of relations or friendship. As the number of connections increases, a large set of connected individuals, called giant component of the network, is generated. The larger the component, the better the interconnection among adolescents.

- Diameter of the giant or connected component: the maximum separation between two adolescents, also called diameter of the giant component, measures the widest distance to be covered to connect two individuals in terms of interposed nodes. Obviously, this calculation excludes non connected individuals.

- Average distance or degrees of separation: for a given individual, his or her friendships will have a degree of separation equal to 1 , while the friends of his or her friends will have a degree of separation equal to 2 with the original individual and on and on. Based on the calculation of the minimum distance between two pair of adolescents in the network, the average separation distance is obtained for the set of connected individuals.

- Clustering: most of the individuals in a social network are associated in community clusters with similar affinities; in the case of adolescents, there could be clusters of friends separated by gender or consumption habits. To try the formation of clusters, the $C$ cluster coefficient is calculated based on the following expression:

$\mathrm{C}=3 \times$ number of triangles in the network / number of triplets of connected vertexes

Where the "triangle" corresponds to a trio of friends, all of them interconnected, and a "connected triplet" is the only individual connected to other two individuals. Therefore, the $\mathrm{C}$ coefficient is valid when there is a completely connected network (all individuals are connected to everybody); while if connections are at random, or if they do not form a specific cluster, the $C$ coefficient will approach a zero value $(1 / \mathrm{N}, \mathrm{N}$ being the number of nodes in the network), as in the case of a randomly built network. 


\section{Electronic annex. Structure of the survey}

\section{NETWORKS IN SCHOOL ATTENDING ADOLESCENTS}

\section{GENERAL DATA}

No. assigned to the surveyed adolescent:.

Date:.../.../...

School:

\section{PERSONAL DATA}

Surname:

Age:.... years...

Home Address:

Year attending:

Weight:..... kg.

$\mathrm{BP}$............mmHg.
Survey taker:.......

Names:

$\mathrm{N}^{\circ}: \ldots$.

Schooling hours:....h.

Waist circumference:......cm.

\section{BEST BONDS WITH SCHOOLMATES}

In the following box, write the First Name and Surname of students that attend your school with whom you have the best relationship of friendship or comradeship. Write their names down in order of importance. Do not write in the column of the assigned number, the survey taker will do it.

First name and surname of the schoolmate with the best bonds. Assigned No.

(Up to 10 friends can be included)

\section{FOOD}

Do you eat candies at school? $\quad$ Yes $\square$ No $\square$

Do you eat sandwiches or hamburgers or hot dogs at school? Yes $\square$ No $\square$

Do you frequently do it in company with some of the individuals you cited as your best friend or buddy? Yes $\square$ No $\square$

Do you watch your weight or follow a diet to lose weight? Yes $\square$ No $\square$

\section{SMOKING}

Did you ever smoke in your life?

Have you smoked in the last six months?

Do you smoke on a daily basis?

Yes $\square$ No $\square$

If you smoke, do you do it to lose weight?

Yes $\square$ No $\square$

Yes $\square$ No $\square$

Yes $\square$ No $\square$

\section{PHYSICAL ACTIVITY}

Do you practice sports? (either to compete or not): $\quad$ Yes $\square$ No $\square$

What sport do you practice more frequently?:
Soccer $\square$
Tennis $\square$
Biking $\square$
Hockey
Others $\square$

How often do you practice a sport per week? Once or twice $\square \quad$ Three times or more $\square$

\section{SPARE TIME}

What do you generally do in your spare time?:

Watch TV

Play with videogames

Read

Play games or practice sports

\section{ALCOHOLIC BEVERAGES}

Do you drink alcohol containing beverages?: Yes $\square$ No $\square$

How often do you drink alcohol containing beverages (beer, wine, champagne, whisky, fernet, tequila, vodka, etc.) per year?: $\quad$ Once $\square \quad$ Twice $\square \quad$ Three times or more $\square$

Where do you have alcohol beverages more often?:
At the dancing club
At the bar
At my friend's home
At home 